\title{
The Twenty-Seventh Annual Meeting, June 1998
}

The Twenty-Seventh Annual Meeting of the College was held at the Waterfront Centre, Belfast, Northern Ireland, on 22-25 June 1998.

\section{Business Meeting}

The Business Meeting of the Royal College of Psychiatrists was held on Wednesday 24 June 1998 and was chaired by the President, Dr Robert Kendell. It was attended by 62 members of the College.

The minutes of the previous meeting held in Bournemouth on 2 July 1997, and published in the Psychiatric Bulletin, December 1997, were approved and signed.

The Report of the President was received. Included in this Report was a proposal to amend the Bye-Laws concerning the election of Honorary Fellows. This election had previously taken place at the Business (General) Meeting held during the Winter Meeting of the College, but the abolition of this Meeting necessitated changing the procedure.

Four possible courses of action were considered, and it was agreed that the following option was most appropriate. A General Meeting of the College would be convened to take place after the January meeting of Council. Details of this Meeting and information about the recommendations for Honorary Fellows would be published in the Psychiatric Bulletin.

The Report of the Registrar and the Annual Report were received and approved. The Report of the Treasurer and the Annual Accounts for 1997, as given in the College's Annual Report. were received and approved. The re-appointment of the auditors was approved. The new fees and subscription rates from 1 January 1999 were approved. The Report of the Dean was received. The Report of the Editors was received. The Report of the Librarian was received.

The following Resolution was proposed by $\mathrm{Dr}$ Robert Kendell and seconded by Dr Mike Shooter:

That the Bye-Laws of the College be amended. revoked and added in accordance with the copy thereof containing such amendments, revocations and additions sent to the Members with the notice of this Meeting provided that such amendments, revocations or additions shall not take effect until the same shall have been approved by the Privy Council and provided further that the Executive and Finance Committee of the Council shall have authority to approve any further amendments required thereto by the Privy Council.

Pursuant to paragraph 12 of the Supplemental Charter of the College the said Resolution is to be approved by a majority of not less than two-thirds of the Members of the College present and voting at the Meeting.

It was agreed, after discussion, that the Research Committee should retain its title and not change this to the Research. Audit and Informatics Development Committee. Otherwise, the Resolution was supported.

\section{President's Report}

The President reported on activities undertaken by the College officers in response to the Resolution passed at the Annual General Meeting in 1996. The College's main aims had been to convince the Government that community care' was indeed in a state of crisis in London and other big cities, and that urgent action was needed to tackle psychiatry's serious manpower problems. These aims had largely been met. The Department of Health was itself anxious to increase staffing levels in psychiatry, several useful initiatives had been mounted and the situation was now improving. Although there were still over 400 unfilled consultant posts the number of consultants in post was increasing steadily. Recruitment to senior house officer posts had improved as well. It was also clear that the new administration accepted many of the College's criticisms of community care and likely that its new policy initiative, which was expected within weeks, would lead to significant improvements as well as providing much needed additional funding. The College would continue to do all it could to persuade the Government to abolish mandatory homicide inquiries, managers' reviews and the supervision register and to simplify the bureaucracy of the Care Programme Approach.

Dr Kendell also drew attention to the need for the College to do everything in its power to correct the shortcomings in the delivery of electroconvulsive therapy in many hospitals revealed by its own audits - inadequate consultant supervision, inadequate training of senior house officers and in some cases the use of obsolete equipment. He reminded all College members with any responsibility for electroconvulsive therapy of the importance of providing the best possible service to patients in this politically sensitive area. 


\section{Registrar's Report}

The Registrar noted that anyone who had visited 17 Belgrave Square recently would be aware that a great deal of building work had been carried out, both inside and outside the building and that great improvements had been made. As far as progress regarding community care was concerned, Dr Shooter observed that, while the College welcomed in spirit the Sainsbury Foundation's document, 'Building Comprehensive Mental Health Services,' it could not approve all it said. The report of the Independent Reference Group: 'Positive Approaches' was disappointing in its archaic distinction between medical and social models and an insistence on the failure of community care as an idea rather than the failure to resource it properly. It would be interesting to see how the College's relationship with the Government on this issue progressed.

Consultant staffing continued to be a problem, although the number of consultants in post had increased slightly and the number of vacancies in some specialities had decreased. Some geographical areas and specialities were, however, still struggling. There was a growing tension between two, parallel, and often competing, College structures: the Faculties, which were flourishing, and the Divisions, most of which were not.

The results of the President's fascinating postal questionnaire of members' activities and attitudes showed just how entrenched was the mythology that the 'College' was a London-based, academic-dominated, old boy network of little grassroots relevance. Dr Shooter observed that some hard work would be necessary to remedy this. A healthy debate had started about the dependence of some College activities, especially Public Education, the Research Unit and Meetings on drug company sponsorship. Professor Chris Thompson. Vice President, was looking for new ways to raise money for these activities through a semi-separate charity.

The Registrar reported that life for the medical Royal Colleges would never be the same after recent incidents at Bristol; all Colleges were looking at the possibility of developing their own. rapid-response, investigatory teams which would respond to the anxieties of trust managers.

Following the College's review of its own Divisional structure, the configuration of the National Health Service (NHS) regional offices in the South and West of England were again reorganised; a decision would shortly need to be taken on whether the College once more reorganised its geographical structures.

The Court of Electors had voted to make six months of child and adolescent psychiatry, learning disabilities or a combination of the two a mandatory part of training for the membership.
Numerous working parties were beginning work: the Mental Health Needs of Children of Mentally Ill Parents; the Aftercare of Violent and Vulnerable Patients Discharged from In-Patient Care and the Ethics of Research on Human Subjects. Also, new Council Reports had been prepared on videotaping, on deliberate self-harm and on gender identity disorders in children and young people, and the College Research Unit had produced its first set of guidelines, on the management of imminent violence.

\section{Treasurer's Report}

The Treasurer reported that the Accounts netted a healthy surplus for the year, and that the current health of the College was due to a combination of factors: sensible budgeting by all the College departments, led by the College Secretary and the resourceful and skilled professional monitoring and stewardship of the Finance Department staff under the direction of the Head of Financial Services. However, there were other important contributions, publications usually provided a welcome surplus and also the wherewithal for complimentary journals for members, successful College meetings and the improved performance by our investment managers.

For the first time in years it had proved possible to incur some essential major expenditure - notably the purchase of the College flat. the building of a roof extension, the embarking on a programme of redecoration and refurbishment of the College which had become rather shabby, the upgrading of information technology which was likely to cost about one-quarter of one million pounds over the next three years. A number of other initiatives had been enabled including writing off the debit balance of Faculties and Divisions, complemented by a system of subsidies for Faculties, Divisions and Groups; and establish a satellite office in Wales; other consequences would be of direct benefit to the members such as keeping the annual increase in membership subscriptions to marginal levels with an average of about three per cent, and for some categories of membership there had been no increases; and also to recommend only a marginal increase of the examination fees. It had also proved possible to waive charges for central staff costs to the College Research Unit and also to allocate funds for pump-priming of the new anti-stigma campaign.

Finally, it had been agreed that there would be a substantial reduction in conference fees both for inceptors and retired members. The Treasurer was pleased to note that these were. indeed, better times. But such better times were 
not a licence to spend since there remained a need to plan for the future. It was noted that there was never a paucity of good ideas requiring financial support from the College. All bids continued to be subject to the self-same scrutiny and questioning that occurred in hard times only now more bids got past the winning post.

\section{Dean's Report}

Professor Cox reported on several items of ongoing business within the Departments of Postgraduate Educational Services and Examinations. The pass rate at Part II MRCPsych was $53 \%$, which was slightly higher than previous examinations; there had also been several important changes to the examination. Competition for senior house officer posts had increased very considerably. The College was represented in ongoing multi-professional work initiated by the Sainsbury Centre, discussing the practical implications of their report, 'Pulling Together'. Professor David Cottrell, Sub-Dean for Education and Dr Anne Dean, Head of Postgraduate Educational Services, continued to extract educational objectives from College policy documents to ensure no crucial training issues were overlooked.

The proposal to develop a video or CD-Rom on safety, particularly for trainees had recently been agreed and, with the full collaboration of the new Dean, the Education Committee recently discussed a procedure for reviewing the educational strategy of the College in the autumn. Professor Cox reported that the preliminary report on the Survey of Flexdble Trainees in Higher Specialist Training was now available.

An overview of the Defence Medical Services Psychiatric training was recently initiated because of the need to balance training programmes fully consistent with work within the NHS as well as the specific training necessary for working as a psychiatrist in the Armed Forces. The Dean also reported on work resulting from a joint working party between the College and the Department of Health to establish the optimum method of distributing the names of consultants with an interest in transcultural psychiatry.

\section{Editor's Report}

Professor Wilkinson reported that the British Journal of Psychiatry had a competitive impact factor. Four supplements had been published this year which should make a financial impact next year. An article would shortly appear on editorial decision-making in line with the policy of transparency. Professor Wilkinson reported that Dr Alan Kerr had relinquished Editorship of the Psychiatric Bulletin after 27 years of distin- guished service. Dr Kerr would continue in his role as Deputy Editor of the British Journal of Psychiatry. Dr Tom Fahy had taken over as Editor of the Psychiatric Bulletin. Professor Andrew Sims continued successfully to edit Advances in Psychiatric Treatment which had 2400 subscribers. Dr Alan Lee had edited two books derived from Advances in Psychiatric Treatment which should be of great value to trainees in psychiatry, one dealing with the psychoses and the other with the neuroses.

The College had joined together with the British Medical Journal in the publication of EvidenceBased Mental Health. The book programme continued to expand, the best-selling books were in the College Seminar series and, since its introduction in January the two volumes on general adult psychiatry had sold in excess of 700 copies. Professor Wilkinson drew attention in particular to the series of Books Without Words, developed by Professor Sheila Hollins as worthy of wide attention, particularly in relation to people with learning disabilities. Professor Wilkinson announced that he had commissioned a series of special sections for the British Journal of Psychiatry dealing with scientific advances relating to each of the Faculties of the College.

Professor Wilkinson once again thanked everybody involved with publications for their tremendous efforts.

\section{Librarian's Report}

The Librarian reported that libraries everywhere were changing to meet the increasing demand for up-to-date information - the College Library was no exception. A radical review of the Library's role has taken place, the first such review for decades. The Library was founded 103 years ago when Dr Daniel Hack Tuke bequeathed his library to the Royal Medico-Psychological Association. It has been in its present form since the College was founded and moved to Belgrave Square 27 years ago. Since then, all available space in the Library has been used up, and overflowed into cupboards and shelves throughout the building.

The Librarian concluded that, while most of the key functions of the Library should be retained, the focus should shift to a greater provision of current information. The book collection should be culled significantly, with the help of experts nominated by Faculties and Sections, to reduce overcrowding. The emphasis should be on providing a reflection of members' works published within the past five to 10 years, and key texts in the development of the field of psychiatry. A critical review would be made of journals with a view to disposing of those which are never used. Space freed up as a result of this would be devoted to enhanced access to the electronic media and space for members to use. 